\title{
Interactive comment on "Should altitudinal gradients of temperature and precipitation inputs be inferred from key parameters in snow-hydrological models?” by Denis Ruelland
}

\section{Anonymous Referee \#1}

Received and published: 27 December 2019

This paper presents a nicely conceived study where several alternative approaches for distributing temperature and precipitation are compared in a mountain region (French Alps). In addition to standard interpolation approaches based on inverse-distance weighting and Kriging, the author explores the possibility of optimizing lapse rates as part of a snow-hydrologic-model calibration procedure. Results of a split-sample test show that the latter approach provides improved results for the target variables considered during calibration, that is, fractional snow cover (FSC) from MODIS, streamflow, and the water balance. Also, optimizing the temperature and precipitation distribution algorithm with hydrologic data results in the temperature and precipitation fields being colder and wetter than those obtained by using only in-situ measurements of temper-

Printer-friendly version

Discussion paper 
ature and precipitation, respectively; this result agrees with expectations, especially since the considered ground-based network is not representative of high elevations in the study catchments.

I enjoyed reading the manuscript and I think it represents an interesting contribution for HESS, especially because the investigated topic is a clear open issue in mountain hydrology. I do have several general and specific comments, which I attach below. Overall, I think that the revision is feasible.

\section{GENERAL COMMENTS}

1. in my understanding, the author essentially compares two main strategies: the first is to regionalize temperature and precipitation based on in-situ data and various interpolation/extrapolation schemes based on IDW or Kriging (Section 3); the second is to "embed" part of the distribution process into the snow-hydrologic models via lapse rates that will correct a first-guess distribution based on IDW (see Section 4, Table 2 and 5 and Equations 9 and 10). While the first approach is independent from hydrologic data like fractional snow cover and streamflow, the second does take advantage of these data to adjust some of the distribution parameters. In my understanding, the main point of the paper is that the second strategy is superior to the first, especially since adjusting snow parameters rather than precipitation-distribution parameters does not allow the model to significantly improve its performance (see Table 5 and Fig. 5). Unless I am missing something here, this improvement was however assessed based on the same hydrologic variables that were used to calibrate the snow-hydrologic models, rather than on independent measurements of the two variables of interest: temperature and precipitation. This left me wondering if this experiment shows that "calibrating the local gradients using an inverse snow-hydrological modelling framework" improves actual temperature and precipitation estimates, or if it shows that it improves hydrologic predictions. In principle, one would expect the obtained altitudinal gradients to be both more effective in terms of hydrologic predictions and in terms of temperature and precipitation, but the improvement obtained by "embedding" part of the distribu-

Printer-friendly version

Discussion paper
Interactive comment 
tion process into the snow-hydrologic models is quantified in terms of modeling skills for fractional snow cover, streamflow, and the water balance (Figs. 5 to 8 ) rather than for independent estimates of temperature and precipitation. If independent data of temperature and precipitation at high elevations are not available, then I would recommend the author to clarify the extent to which these results apply to temperature and precipitation in addition to hydrologic variables.

Interactive

2. The point above is particularly important since hydrologic models may suffer from several sources of conceptual and parametric uncertainties, some of which are visible in the interesting Figure 8. It follows that an improved fit for hydrologic variables may not automatically mean that the model is also better representing weather patterns of temperature and precipitation. A good example here is that the obtained lapse rates (Fig. 9) can locally be quite different between the two hydrologic models considered. To me, this may challenge the idea that this approach could be used to "infer local altitudinal gradients from a sparse network of gauges based on key parameters in the snow-hydrological models" (L 592ff). It does suggest that the method improves hydrologic predictions, but implications for actual temperature and precipitation are more elusive to me and should be discussed more extensively.

3. Related to this, both hydrologic models were used in lumped mode (L340), even if several other modeling approaches explicitly account for spatial variability in hydrologic processes (e.g., raster-based models). At least some discussion on this point would be interesting.

4. Spatial variability was considered in the snow model, which was implemented along five elevation bands in each catchment. This model does include all fundamental snow processes, but in my understanding does not include a specific provision for wind drift. Relying on FSC from MODIS may sometimes lead to confounding effects in this regard, where wind-driven accumulation and erosion is mistakenly assumed as due to precipitation or melt. Was this somehow taken into account here, or could the author suggest how to include this in the framework?

Printer-friendly version

Discussion paper 
5. I am also interested in the different outcomes of this analysis for precipitation between the daily and the annual time scales (table 4). Maybe one key to interpret this result is that summer vs. winter precipitation patterns are different, and the in-situ network might be more representative of the former than of the latter (or vice versa). I am thinking to convective precipitation here, which sometimes show significantly different elevational gradient from stratiform or orographic precipitation. Some more discussion on precipitation regimes could be interesting in this paper.

\section{SPECIFIC COMMENTS}

- Line 149: is this because no gap was originally present in the dataset, or because these gaps were filled? If the second, maybe briefly mention how.

- Section 2.1: a histogram with the elevation distribution of in-situ stations may be helpful, along with more details about the climatology of the study period (annual mean temperature and precipitation, annual runoff etc). Doing so may help the author to set the context of the analysis, especially for non-local readers.

- Section 2.2: is any of these catchments glacierized? If so, how were glaciers considered in this framework? If not, may glaciers hamper the applicability of this method in other regions, especially with regard to the mass-balance-closure term in Eq. 12 and Fig. 6?

- Section 2.3: the approach by Gascoin et al. 2015 was, to my knowledge, developed in the Pyrenees, a mountain range with significantly lower elevations than the Alps. How was the method adapted for the French Alps? Is the performance similar to that originally published by Gascoin et al. 2015 in a different mountain range?

- Line 263ff: was mean precipitation computed across the whole study region? Might doing so exclude more localized precipitation events in favor of more widespread stratiform events?

Printer-friendly version

- Title of Section 4: ASSESSSMENT -> ASSESSMENT

Discussion paper 
- Section 4: a table with the list of all parameters considered by the snow and hydrologic models would be helpful, including an explicit statement of which parameters where calibrated. Some of these parameters are only mentioned at the very end of the manuscript (Section 5.3).

- Line 321: this should in fact be evaporation to me, since there is no transpiration in the snow module (correct?)

- Section 4.3.1: where the two periods similar in terms of snow conditions and streamflow, as well as mean temperature and mean precipitation across the in-situ network?

- Eq 12 and Section 4.3.2: does the third component of the OF assume that interannual variability in subsurface storage is negligible? This might not be an issue in the studied area, but it may be worth mentioning this in case interested readers would like to apply this approach somewhere else. In fact, results in Section 5.3 do suggest that interannual sub-surface dynamics are worth discussing.

- Section 5.1: do statistics reported in Fig. 4 and at lines 406ff consider areas outside the studied catchments too, including Italy and Switzerland? It might be better to report statistics for the French Alps only here since this is where data were available to this study.

- Section 5.2: the first paragraph of this section and Table 5 should be moved to the Methods. It should also be clarified that each re-calibration mode included hydrologic parameters too (correct?)

- Fig. 6: it seems like all data are within the boundaries given by the water and energy limit. I am not an expert of this approach and was wondering why one should aim to obtain "the least stretched and dispersed cluster". More details on this might be helpful for other readers too.

- Line 490ff and other similar passages of the manuscript: in fact, this result suggests to me that correcting for precipitation and temperature distribution has a stronger impact 
on model predictions than adjusting for other snow-related processes like phase partitioning or melt, rather than that "adapting to local snow processes is not indispensable". To me, other processes are important too, but correctly estimating total accumulation is likely the most important one here.

- Section 5.3: I would probably add more details about how parameter identifiability is quantified from Figure 8.

- Line 610 and, earlier, line 490: how were these "physical or general values" obtained?

Interactive comment on Hydrol. Earth Syst. Sci. Discuss., https://doi.org/10.5194/hess-2019556, 2019. 